\title{
Automation conditions of mobile base station shelter via cloud and IoT computing applications
}

\author{
Ahmed Hussein Shatti, Haider Ali Hasson, Laith Ali Abdul-Rahaim \\ Department of Electrical Engineering, University of Babylon, Iraq
}

\begin{tabular}{l}
\hline \hline Article Info \\
\hline Article history: \\
Received Oct 22, 2020 \\
Revised Feb 22, 2021 \\
Accepted Mar 3, 2021 \\
\hline
\end{tabular}

Keywords:

BTS shelter

Cloud computing

Firebase cloud

IoT

Raspberry Pi 4

\begin{abstract}
In this paper, a monitoring and controlling process of the mobile base station shelter has been implemented. We have proposed a model that is based on a firebase cloud service and the principle of the internet of things (IoT) to carry out the process of automation. In this model, we have used Raspberry Pi 4 as the main microcontroller of our system that has interacted with a DHT11 Humidity-Temperature sensor and a PIR motion sensor. It's found that the Pi4 module provides efficient analysis, low consumption of power, and effective control of the operation. It turns ON/OFF the electrical appliances automatically inside the shelter. The main advantage of our proposed model is to maintain the temperature and humidity degrees inside the shelter within the required range of operation. Another important advantage is to diminish the tall human exertion level behind the monitoring process throughout the day. The model has been tested through a localhost server via an HTML page. The last one was created with the assistance of HTML and CSS languages to be used as a local user interface. Moreover, the Raspberry Pi 4 was programmed by Python Language to catch up on the reading of the sensors, processes the data, and sends it to the cloud service. Finally, those data will be shown in real-time to the authenticated user on the database of the firebase cloud service.
\end{abstract}

This is an open access article under the CC BY-SA license.

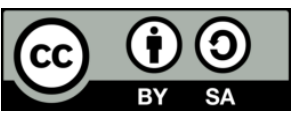

Corresponding Author:

Ahmed Hussein Shatti

Department of Electrical Engineering

The University of Babylon

Hilla-Najaf Road, Babylon, Iraq

Email: eng.ahmed.hussein@uobabylon.edu.iq

\section{INTRODUCTION}

The mobile base station (BTS) is a telecommunication infrastructure that is used to facilitate wireless conversation between the subscriber terminals and telecommunication network operators. The subscriber system can be a cellular phone, wireless web unit, whilst the operator could be a CDMA and GSM. Every BTS composes of a transceiver, combiner, power amplifier, duplexer, and antenna. All these elements, except the antenna part, are usually housed in a small room called a "Shelter". The latter protects the mobile base station equipment from external conditions such as dust, rain, rust, corrosion. The temperature degree of the shelter may be raised to $55^{\circ} \mathrm{C}$ during the operation of the BTS. In such a case, the electronic equipment of the BTS will operate under a bad condition of temperature degree. To solve this problem, an air-conditioner should be installed inside the shelter. The air-conditioner will reduce the hightemperature degree and cools the space to about $25^{\circ} \mathrm{C}$. However, to make this process done in an automated way throughout the day, in this paper, a proposed technical solution has been suggested. Our proposed solution depends on the IoT principle [1]-[5] and the firebase cloud service computing [6]-[8]. Monitoring 
the equipment of the BTS, reading sensor measurements, and storing the information through the internet, all these functions have been implemented through our work with the help of the Raspberry Pi4 module. Shelter room automation based on IoT architecture supplies a flexible way of communication, connectivity, data analysis, and device management [9]-[15]. In contrast, one of the major merits of cloud computing [16] is that the elasticity of the location and time to the user. However, the cost will significantly reduce when the powerful processing infrastructure is provided by the third party. Thus, the necessity of buying a powerful computing device is not required.

Many related works that have used IoT and cloud technologies will be discussed here in the following lines. Wan et al. [17], the author has been presented a novel "Wearable IoT-cloud-based health monitoring (WISE)" system that specialized in monitoring the patient's real-time health. This system uses a group of sensors placed in different areas of the body. Such sensors including a heartbeat sensor, temperature sensor, and sensor for the pressure of the blood. However, the smartphone has been used as a gateway for data processing like monitoring, visualization, and transmission, this may indeed increase the importance of the daily use of these devices. Vaidya and Vishwakarma [18], to make life easy by minimizing human effort, smart home automation and remote control of all applications at the home were prepared. The work in [19] has prepared a series of smart home designs. It deals with IoT's design, they offered a way that remotely controls the smart home through utilizing an IR infrared sensor. An intelligent structure system that is used for smart home metering has been implemented in [20]. The major goal of this type of system is to supply real-time information for monitoring and controlling the home appliances. It is keeping up-to-date information about appliances inside the home such as ON/OFF state, consumption of power, failure operation, or appliance malfunctions. Pătru et al. [21] has provided a solution for connecting more devices to a signal entity that is easily accessible at any time. Automation for office-room architecture in a real-time mode based on the IoT system has been considered. Singh and Shimi [22], automatically turning ON/OFF of the electrical appliances, taking care of room circumstances have been considered. However, based on the "LPC2148 ARM-7" controller, anyone enters the automated room, the lights of a concrete section will automatically get turn ON. The action control of the proposed system is to monitor the comfortable temperature of the room by turning ON/OFF the existing appliances.

Yang et al. [23] has built a "CSI-enabled IoT" platform-model that is used for environmental sensing inside the smart home. A proposed model based on cloud service has been applied for the environments of the smart home in [24] for lighting overcasting system. In comparison with existing works, our model completely merges the mobile base station across the Wi-Fi device to the cloud service on Google which is the firebase cloud service. It provides an efficient solution for showing the temperature and humidity degrees of the mobile base station in real-time. Both degrees have been recorded in terms of Celsius and RH degrees, respectively. One of the major contributions of our model is that it helps in prolonging the life of the BTS equipment. Otherwise, it reduces the consumption of power over the whole BTS. The performance of our work has been shown an acceptable BTS monitoring process anywhere, anytime, and with little human effort. However, a group of networking sensors [25] like thermal camera sensor, power failure sensor, motion sensor, ambient temperature and humidity monitoring sensor, battery leak sensor, DC voltage sensor, hydrogen (H2) sensor, smoke sensor, door contact sensor, grounding sensor, dust sensor, and many others that can be utilized to make full automation of the cell unit station. The rest of our paper is organized is being as: Section 2 offers a group of facilities that have been used in our research method. Section 3, describes our proposed model and how the mobile base station can be integrated with the IoT platform and cloud service. Section 4 shows the expected results of our proposed model. At last, the work and evaluations as well as some of the future work are concluded in section 5.

\section{RESEARCH METHOD}

In our research method, we have used the following facilities:

\subsection{Raspberry Pi 4}

The Raspberry Pi4 module is a mini motherboard computer that has its file system, desktop, and operating system. The last one can be downloaded from the official site of the company and stored on a micro-SD card memory. The Pi4 module feeds a set of GPIO "general-purpose input/output" pins which serve as an electrical interface to the sensors. On the other hand, the connected appliances to the Pi4 module are controlled via an electronic relay board. There is a lot to do with the Raspberry Pi4. In our work, we have used the Pi4 module to control the physical environment of the shelter as well as to send the data across the web. It is easy to use, a powerful device, cheap, as well as; it is difficult to break. Raspberry Pi4 is an ideal device for ambitious computer scientists [26]. 


\subsection{DHT11 Humidity-Temperature sensor}

Figure 1 shows the DHT11 model of the humidity-temperature sensor [27]. It has a temperature range that begins from -40 to $+80 C^{o}$ with $\mp 0.5 C^{o}$ accuracy. Moreover, the humidity range begins from $0 \%$ to $100 \%$ RH with an accuracy of $\mp 2 \%$.

\subsection{PIR motion sensor}

The PIR motion sensor is shown in Figure 2, as its name implied, it is used for detecting any motion within its zone. It controls the inside lighting of the shelter room by switching ON/OFF the light bulb. It is simple to use, low power consumption, and cheap [28], [29].

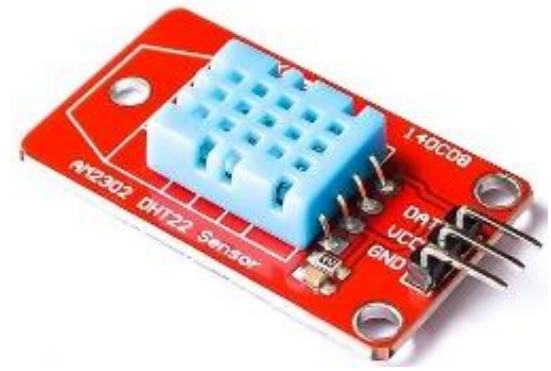

Figure 1. DHT11 humidity-temperature sensor

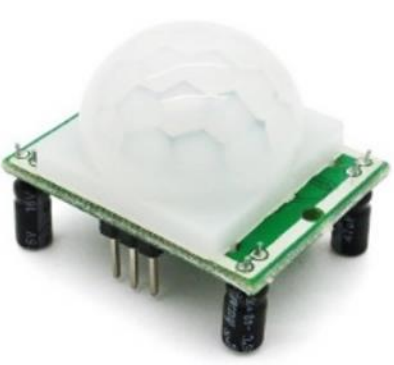

Figure 2. PIR motion sensor

\subsection{Monitor}

Figure 3 shows a $2 \times 16$ liquid crystal display module that has been used to show the humidity and temperature degrees inside the BTS shelter room.

\subsection{Relay board}

The circuit connections of the relay board across the GPIO pins are shown in Figure 4. It has used to switch ON/OFF the appliance connected to it according to the instruction from the Raspberry Pi4.

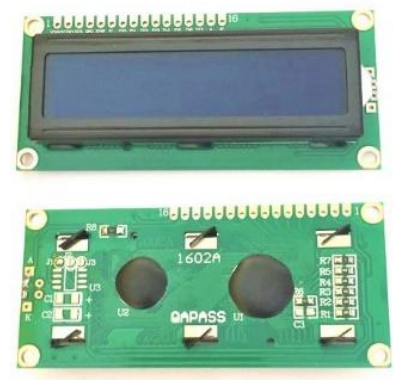

Figure 3. 2x16 LCD display

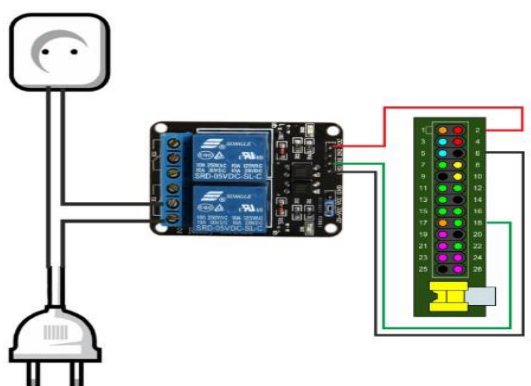

Figure 4. Relay board connections

\subsection{Firebase cloud service}

It has been used the firebase cloud service provided by Google to show the humidity and temperature information of our model in real-time mode to the authenticated user. It's available and free, all you have to need is a Gmail account to create a new project at the firebase service [30].

\section{THE PROPOSED MODEL}

Our project is mainly depending on the cloud computing service. The cloud computing service allows users to access data at any time/anywhere with the help of using web applications. In our proposed model, shown in Figure 5, we have used the firebase cloud service and Raspberry Pi4 module to control the shelter's environment. 
Physically, we have connected the DHT11 and PIR sensors into the GPIO pins of the Raspberry Pi4. The DHT11 sensor has been utilized to harvest the temperature status inside the shelter. While the PIR sensor has been used for detecting any movement inside the shelter. However, those recorded data of the sensors will be transferred to the Pi4 module. Upon these recorded data, the Pi4 will give convenient instruction to the relay board to turn on/off the appliances inside the shelter. At the same time, the Raspberry Pi4 will send all the updates of the DHT11 to the database on the firebase cloud service. However, on the cloud service, the data will be processed in real-time. That is means that the cloud will depict the change in data we sent immediately with a very little time delay. Consequently, this data will be shown to the authenticated user in real time-mode on the firebase database. The flow chart of the whole automation process besides a section of codes written in Python language for the same purpose is shown in Figure 6.

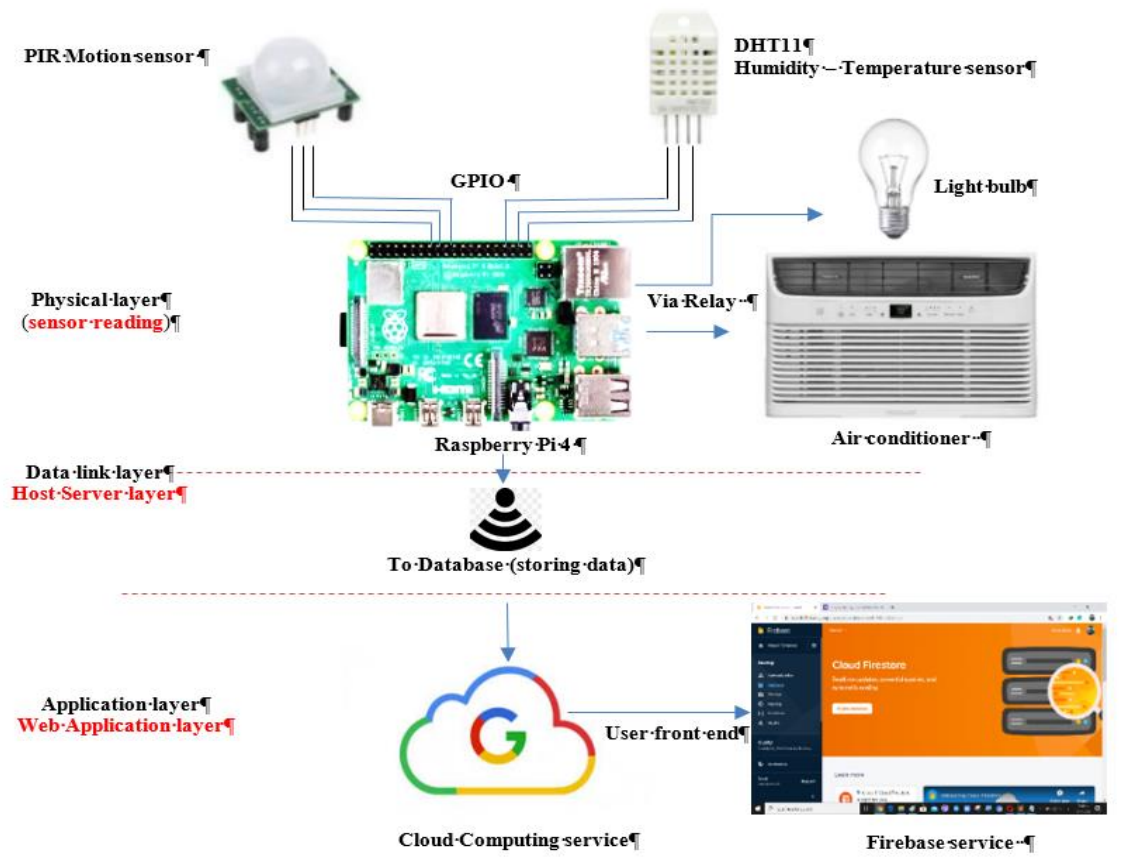

Figure 5. Our proposed model
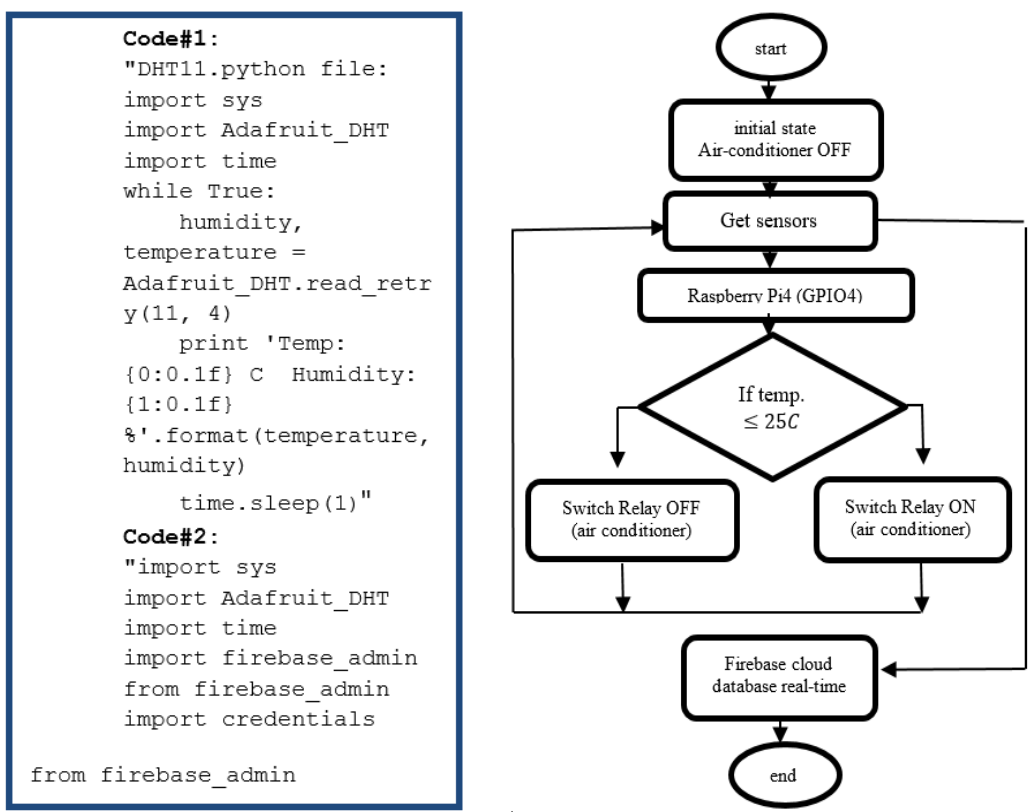

Figure 6. Flow chart and python codes 
The inside of the BTS shelter room and its components are shown in Figure 7. Referring to the flow chart in Figure 6, a set of automatic processing actions on the sensor reading will be implemented by the Raspberry Pi4. The setpoint of the temperature here is $25^{\circ} \mathrm{C}$. It is a convenient temperature degree for the reliable operation of the electronic elements of the mobile base station. If the temperature rises in the BTS shelter room, the DHT11 sensor will record this new value and exchange it with the Raspberry Pi4 to take the required action. In this case, the Pi4 microcontroller will turn $\mathrm{ON}$ the air-conditioner utility.
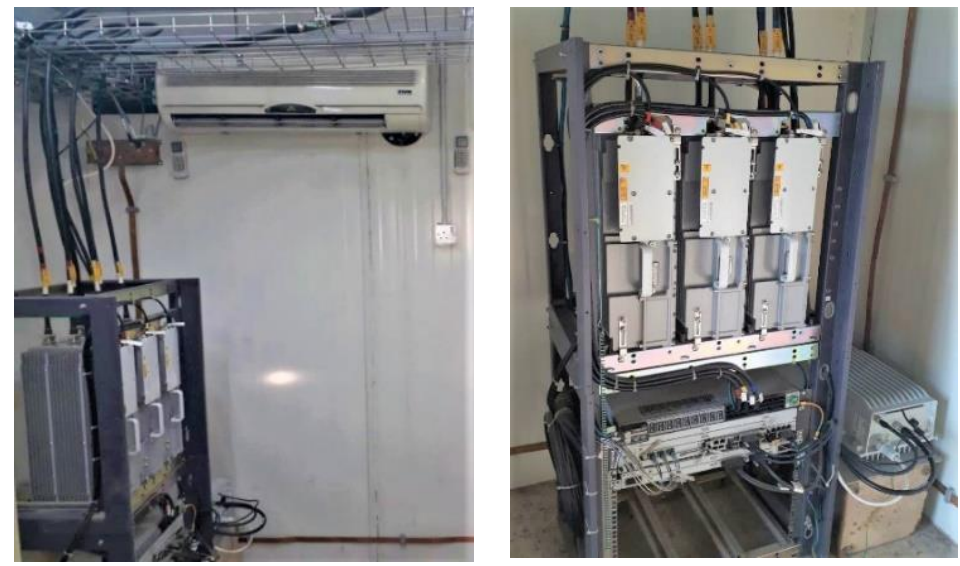

Figure 7. The inside of the BTS shelter room and its component

\section{RESULTS AND DISCUSSION}

Figure 8 shows our results of the temperature and humidity degrees on both the Raspberry Pi4 terminal in our laptop as well as at the firebase cloud database. It appears an acceptable temperature and humidity (31.0 C and 25.0 RH) degrees inside the shelter room of the BTS. For smart and effective realization for the BTS automation system, it is necessary to consider various measurements in the whole BTS. To satisfy this goal, it may be using more than two sensors distributed over the whole area of the station, but they are more expensive. Low-cost sensors like DHT11 and PIR have been used here. They provide a tradeoff between the cost and performance of the operation. The air conditioner utility, as well as the security light bulb, was connected to the Raspberry Pi4 via a relay board. They have switched ON or OFF depending on the status of the temperature, humidity, and motion measurements inside the BTS. At the same time, the information about the temperature and humidity will be sent to the firebase cloud server and monitored there in real-time mode. The same results can be obtained on a localhost server using an HTML page as a local interface shown in Figure 9.

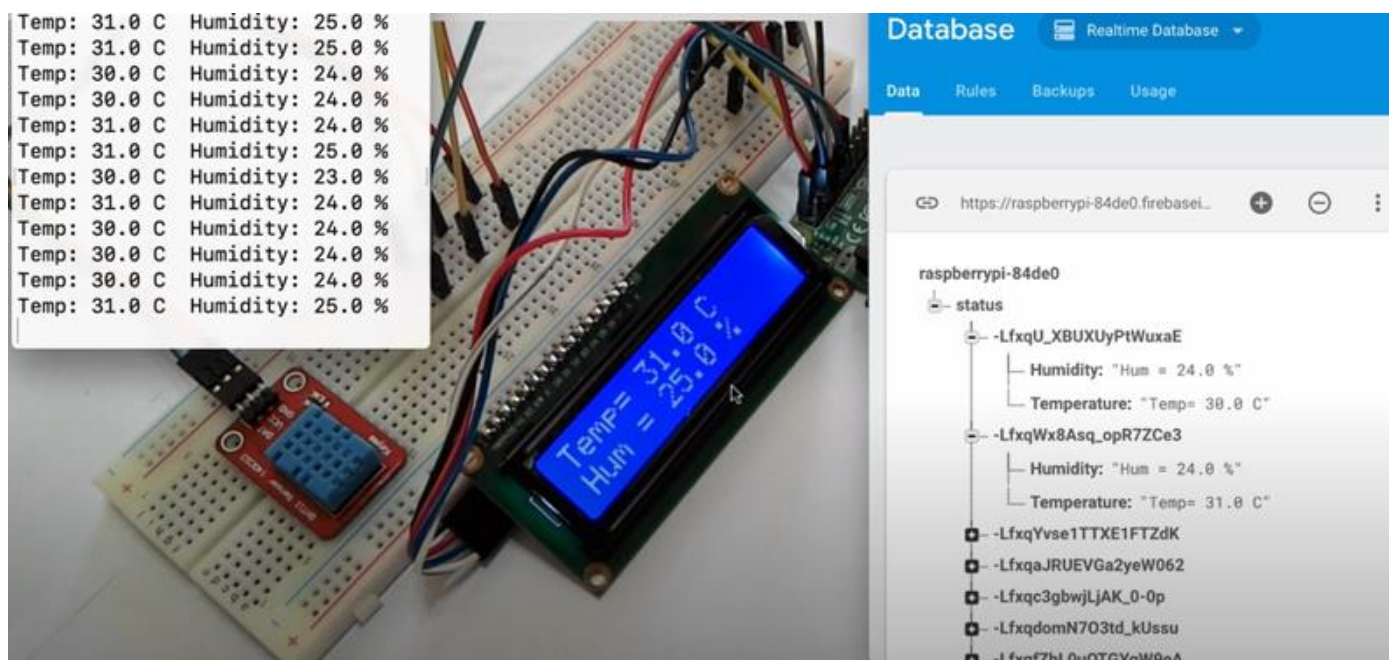

Figure 8. Our model results at the terminal of the Raspberry pi and firebase real-time database with LCD 


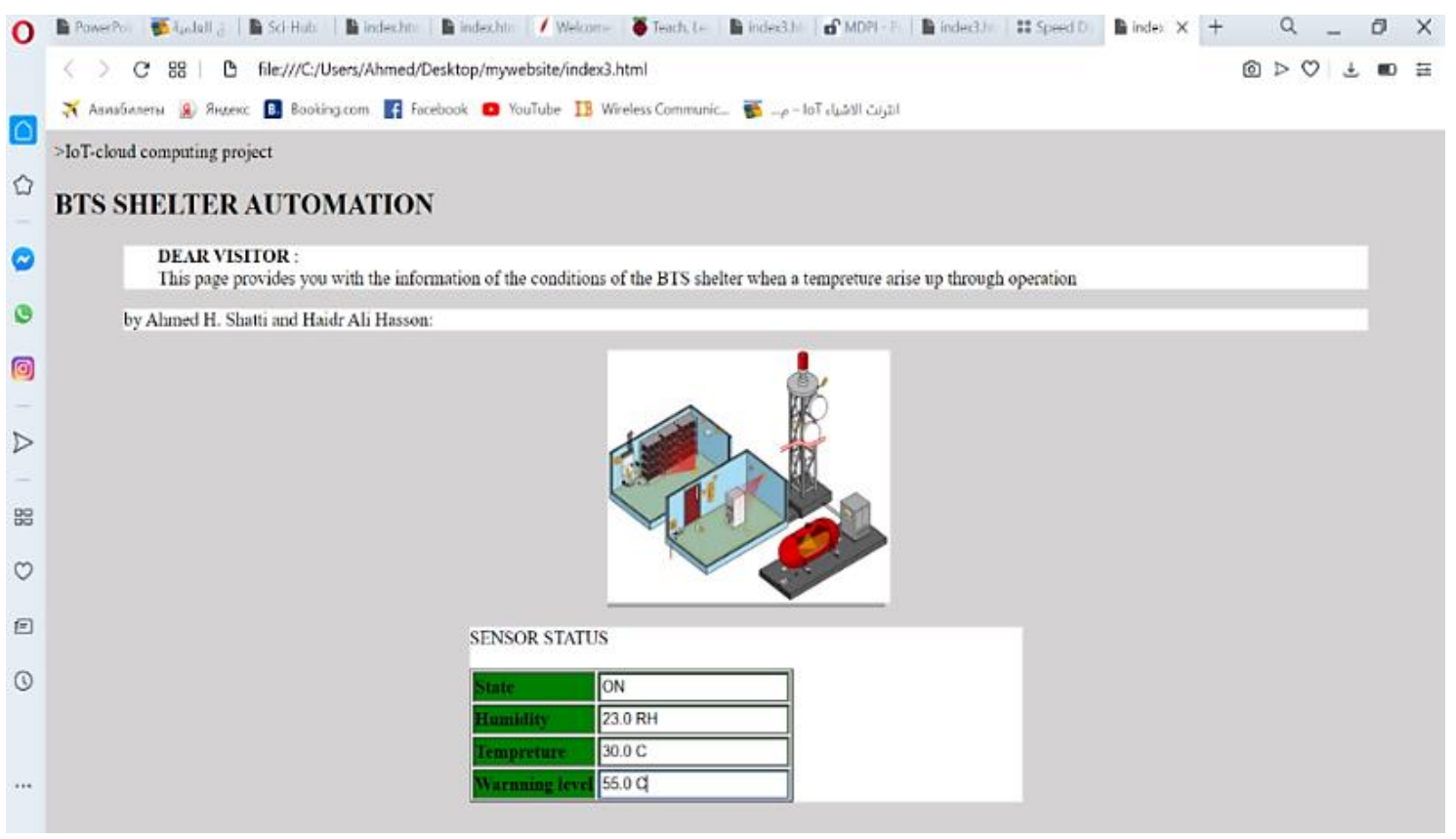

Figure 9. Results of local humidity and temperature on the localhost server

\section{CONCLUSION}

From the automation point of view, our model provides an efficient real-time data monitoring and controlling process. It integrates the mobile base station to the firebase cloud service. A temperature and humidity degree have been recorded and monitored online-on firebase cloud- in real-time operation. The work has been implemented with the help of the Raspberry Pi4 model, the DHT11 humidity-temperature sensor, and the PIR motion sensor. It's found that our proposed model provides low consumption of power, efficient analysis, and effective control operation. Otherwise, reduction in human effort, throughout the day, has been investigated. However, to avoid the outage of the internet connection behind system power failure, a group of buffer batteries must be used to supply the system. Finally, developing a mobile application as a user interface for showing the real-time data on firebase service may be considered as future work. Also, to make full monitoring and controlling process, various types of other sensors can be used inside and outside the BTS area.

\section{REFERENCES}

[1] S. Matilda Florence, M. Uma, C. Fancy, and S. G. Moorthy, "A study of remotely booking slot for a vehicle using Internet of Things," International Journal of Electrical and Computer Engineering (IJECE), vol. 10, no. 5, pp. 5392-5399, October 2020, doi: 10.11591/ijece.v10i5.pp5392-5399.

[2] C. Vijayakumar, M. Senthil, and B. Manickavasagam, "A reliable next-generation cybersecurity architecture for the industrial internet of things environment," International Journal of Electrical and Computer Engineering (IJECE), vol.10, no.1, pp. 387-395, February 2020, doi: 10.11591/ijece.v10i1.pp387-395.

[3] Van-Phuc Hoang, M.-H. Nhuyen, T. Q. Do, and Nhân Lê, "A long-range, energy-efficient Internet of Things based drought monitoring system," International Journal of Electrical and Computer Engineering (IJECE), vol. 10, no. 2, pp. 1278-1287, April 2020, doi: 10.11591/ijece.v10i2.pp1278-1287.

[4] S. S. Patil and A. Biradar, "Novel authentication framework for securing communication in internet-of-things," International Journal of Electrical and Computer Engineering (IJECE), vol. 10, no. 1, pp. 1092-1100, February 2020, doi: 10.11591/ijece.v10i1.pp1092-1100.

[5] H. J. Kadhim and M. J. M. Ameen, "Design and implement a smart system to detect intruders and firing using IoT," International Journal of Electrical and Computer Engineering (IJECE), vol. 10, no. 6, pp. 5932-5939, February 2020, doi: 10.11591/ijece.v10i6.pp5932-5939.

[6] G Dhanush and K. G. Mohan, "Integrated adaptable mobile-based platform for university/college management using firebase," International Journal of Engineering Applied Sciences and Technology, vol. 5, pp. 373-378, May 2020, doi: 10.33564/IJEAST.2020.v05i01.062.

[7] O Sri Nagesh, T. Kumar, and V. Venkateswararao, "A Survey on Security Aspects of Server Virtualization in Cloud Computing," International Journal of Electrical and Computer Engineering (IJECE), vol. 7, no. 3, pp. 1326-1336, June 2017, doi: 10.11591/ijece.v7i3.pp1326-1336.

[8] K. Chandrasekaran, "Essentials of cloud computing," book ( 2015 by Taylor \& Francis Group. 
[9] Dev Gupta, A. Parikh, and S. Rajaguru, "Integrated healthcare monitoring device for obese adults using internet of things (IoT)," International Journal of Electrical and Computer Engineering (IJECE), vol. 10, no. 1, pp. 1239-1247, February 2020, doi: 10.11591/ijece.v10i2.pp1239-1247.

[10] A. Hasan, A. H. Duis, N. Aad, and L. Alzufi, "Smart Monitoring System for Pressure Regulator based on IoT," International Journal of Electrical and Computer Engineering (IJECE), vol. 9, no. 5, pp. 3450-3456, 2019, doi: 10.11591/ijece.v9i5.pp3450-3456.

[11] M. I. Younis and T. F. Hussein, "Design and Implementation of a Contactless Smart House Network System," International Journal of Electrical and Computer Engineering (IJECE), vol. 8, no. 6, pp. 4663-4672, 2018, doi: 10.11591/ijece.v8i6.pp4663-4672.

[12] A. J. Samuel and S. Sebastian, "An algorithm for IoT based vehicle verification system using RFID," International Journal of Electrical and Computer Engineering (IJECE), vol. 9, no. 5, pp. 3751-3758, 2019, doi: 10.11591/ijece.v9i5.pp3751-3758.

[13] R. Mitra and R. Ganiga, "A novel approach to sensor implementation for healthcare systems using internet of things," International Journal of Electrical and Computer Engineering (IJECE), vol. 9, no. 6, pp. 5031-5045, 2019, doi: 10.11591/ijece.v9i6.pp5031-5045.

[14] T. S. Gunawan, I. R. H. Yaldi, M. Kartiwi, and H. Mansor, "Performance Evaluation of Smart Home System using Internet of Things," International Journal of Electrical and Computer Engineering (IJECE), vol. 8, no. 1, pp. 400-411, Feb. 2018, doi: 10.11591/ijece.v8i1.pp400-411.

[15] K. Luechaphonthara and A. Vijayalakshmi, "IoT based application for monitoring electricity power consumption in home appliances," International Journal of Electrical and Computer Engineering (IJECE), vol. 9, no. 6, pp. 4988-4992, 2019, doi: 10.11591/ijece.v9i6.pp4988-4992.

[16] Y. Jadeja and K. Modi, "Cloud computing - concepts, architecture and challenges," 2012 International Conference on Computing, Electronics and Electrical Technologies (ICCEET), Nagercoil, India, 2012, pp. 877-880, doi: 10.1109/ICCEET.2012.6203873.

[17] J. Wan, M. A. A. H. Al-Awalaqi, M.-Song Li, and M. J. O’Grady, "Wearable IoT enabled real-time health monitoring system," EURASIP Journal on Wireless Communications and Networking, vol. 1, pp. 1-10, 2018, doi: 10.1186/s13638-018-1308-x.

[18] V. D. Vaidya and P. Vishwakarma, "A Comparative Analysis on Smart Home System to Control, Monitor and Secure Home, based on technologies like GSM, IOT, Bluetooth and PIC Microcontroller with ZigBee Modulation," 2018 International Conference on Smart City and Emerging Technology (ICSCET), Mumbai, India, 2018, pp. 1-4, doi: 10.1109/ICSCET.2018.8537381.

[19] A. Khan, A. Al-Zahrani, S. Al-Harbi, S. Al-Nashri and I. A. Khan, "Design of an IoT smart home system," 2018 15th Learning and Technology Conference (L\&T), Jeddah, Saudi Arabia, 2018, pp. 1-5, doi: 10.1109/LT.2018.8368484.

[20] T. Balikhina, A. A. Maqousi, A. AlBanna and F. Shhadeh, "System architecture for smart home meter," 2017 2nd International Conference on the Applications of Information Technology in Developing Renewable Energy Processes \& Systems (IT-DREPS), Amman, Jordan, 2017, pp. 1-5, doi: 10.1109/IT-DREPS.2017.8277811.

[21] I. Pătru, M. Carabaş, M. Bărbulescu and L. Gheorghe, "Smart home IoT system," 2016 15th RoEduNet Conference: Networking in Education and Research, Bucharest, Romania, 2016, pp. 1-6, doi: 10.1109/RoEduNet.2016.7753232.

[22] M. Singh and S. L. Shimi, "Implementation of room automation with cloud based monitoring system," 2018 2nd International Conference on Inventive Systems and Control (ICISC), Coimbatore, India, 2018, pp. 813-717, doi: 10.1109/ICISC.2018.8398911.

[23] J. Yang, H. Zou, H. Jiang and L. Xie, "Device-Free Occupant Activity Sensing Using WiFi-Enabled IoT Devices for Smart Homes," in IEEE Internet of Things Journal, vol. 5, no. 5, pp. 3991-4002, Oct. 2018, doi: 10.1109/JIOT.2018.2849655.

[24] C. Hu et al., "IoT-based LED lighting control in smart home," 2018 IEEE International Conference on Applied System Invention (ICASI), Chiba, Japan, 2018, pp. 877-880, doi: 10.1109/ICASI.2018.8394405.

[25] "Proactive monitoring for Edge and critical facilities," https://serverscheck.com/solutions/

[26] R. I. S. Pereira, I. M. Dupont, P. C. M. Carvalho, and S. C. S. Juca, "IoT embedded Linux system based on Raspberry Pi applied to real-time cloud monitoring of a decentralized photovoltaic plant, " Measurement, vol. 114, pp. 286-297, doi: 10.1016/j.measurement.2017.09.033.

[27] M. Soliman, T. Abiodun, T. Hamouda, J. Zhou and C. Lung, "Smart Home: Integrating Internet of Things with Web Services and Cloud Computing," 2013 IEEE 5th International Conference on Cloud Computing Technology and Science, Bristol, UK, 2013, pp. 317-320, doi: 10.1109/CloudCom.2013.155.

[28] J. Dutta and S. Roy, "IoT-fog-cloud based architecture for smart city: Prototype of a smart building," 2017 th International Conference on Cloud Computing, Data Science annd Engineering - Confluence, Noida, India, 2017, pp. 237-242, doi: 10.1109/CONFLUENCE.2017.7943156.

[29] Sanjana Prasad, P. Mahalakshmi, A. John, C. Sunder, "Smart Surveillance Monitoring System Using Raspberry PI and PIR Sensor," International Journal of Computer Science and Information Technologies (IJCSIT), vol. 5, no. 6, pp. 7107-7109, 2014.

[30] Divyesh Zanzmeriya and Ankita Panara, "Implementation of Industrial Automation Systems using Raspberry pi by IoT with Firebase," International Research Journal of Engineering and Technology (IRJET), vol. 5 no. 5, pp. 1331-1334, May 2018. 


\section{BIOGRAPHIES OF AUTHORS}
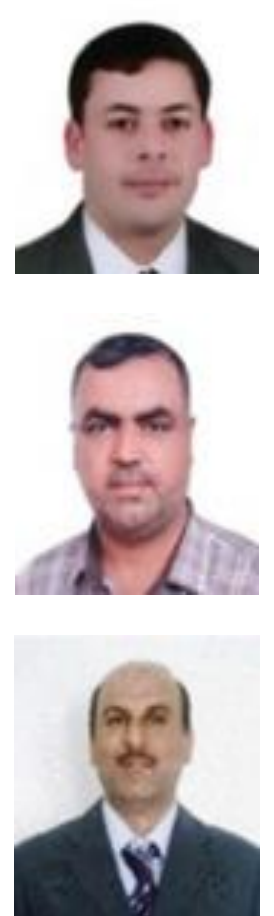

Ahmed Hussein Shatti was born in Babylon-Iraq. He received a B.Sc. degree in electrical engineering from the University of Babylon in 2006 and an MSc degree in communications engineering from the international University of KAI for technology and research in 2013, Russia. He is working as a lecturer at the electrical department/college of engineering at the University of Babylon. He is currently working on his Ph.D. degree in the communication field in the same department at the University of Babylon. His research interests include signal processing, cloud computing, IoT, Massive MIMO.

Haider Ali Hasson was born in Babylon-Iraq. He received a B.Sc. degree in electrical engineering from the University of Babylon in 1998 and an MSc degree in electrical engineering from the University of Babylon in 2015, He is currently working on his Ph.D. degree at the same department in the University of Babylon. His research interests include optical communication, cloud computing, IoT.

Laith Ali Abdul-Rahaim currently works at the Department of Electrical Engineering, University of Babylon. He received a Ph.D. degree in electrical engineering from the University of Technology in Iraq. He researches in Digital Communication Systems Design, Information Science, Communication Security, and Reliability. Now he has a prof. degree in wireless communication. His current project is interested in Smart system Design, and Wireless Communications. 